\title{
Pengembangan Bahan Ajar Bahasa Arab Berbasis Mobile Learning
}

\author{
Muhammad Zul Iman ${ }^{1}$, Muhammad Yaumi ${ }^{2}$, Yusring Sanusi Baso ${ }^{3}$ \\ ${ }^{1,2,3}$ Program Magister Pendidikan Bahasa Arab, UIN Alauddin Makassar, Indonesia

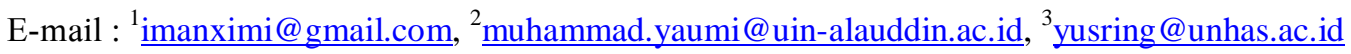

\begin{abstract}
Abstrak : Penelitian ini membahas tentang pengembangan bahan ajar bahasa Arab berbasis mobile learning di SMP Muhammadiyah 1 Makassar. Penelitian ini bertujuan untuk, (1) menganalisis aspek-aspek yang dibutuhkan untuk membangun hal yang ideal dalam pengembangan bahan ajar berbasis mobile learning, (2) mengembangkan bahan ajar bahasa arab berbasis mobile learning, dengan mendeskripsikan tahap-tahap operasional produksi bahan ajar bahasa Arab berbasis mobile learning, (3) menvalidasi produk bahan ajar bahasa arab berbasis mobile learning yang telah dikembangkan. Jenis penelitian ini menggunakan jenis penelitian dan pengembangan (Research and Development) dengan pendekatan penelitian dan pengembangan (R\&D), dimana pendekatan penelitian $R \& D$ merupakan suatu proses yang digunakan untuk mengembangkan dan menvalidasi produk-produk pendidikan. Penelitian ini mengacu pada model pengembangan Hanaffin dan Peck dengan 4 tahap utama yaitu: analisis kebutuhan, desain, pengembangan dan implementasi. Hasil penelitian menunjukkan bahwa produk bahan ajar bahasa Arab berbasis mobile learning telah diuji dan memperoleh penilaian dan validasi oleh ahli bidang masing-masing. Validasi dari ahli materi memperoleh persentase kevalidan sebesar 96.25\% dengan kriteria sangat baik. Validasi dari ahli IT pada aspek desain memperoleh persentase kevalidan sebesar 92.18\% dengan kriteria sangat baik. Hasil validasi terhadap praktisi lapangan menggunakan teknik " $\mathrm{r}$ product moment" (yakni signifikansi $r$ hitung terhadap $r$ table) memperoleh signifikansi $r$ hitung $^{-}$ 0,468 ( $\mathrm{r}$ tabel) sehingga dinyatakan valid.
\end{abstract}

\begin{abstract}
This study discusses the development of mobile learning-based Arabic teaching materials at SMP Muhammadiyah 1 Makassar. This study aims to, (1) analyze the aspects needed to build the ideal in the development of mobile learning-based teaching materials, (2) develop mobile learning-based Arabic teaching materials, by describing the operational stages of Arabic language teaching materials production. based on mobile learning, (3) validate the product of Arabic language teaching materials based on mobile learning that has been developed. This type of research uses the type of research and development (Research and Development) with a research and development (R\&D) approach, where the R\&D research approach is a process used to develop and validate educational products. This research refers to the Hanaffin and Peck development model with 4 main stages, namely: needs analysis, design, development and implementation. The results showed that the product of mobile learning-based Arabic teaching materials had been tested and obtained an assessment and validation by the respective field experts. Validation from material experts obtained a percentage of validity of $96.25 \%$ with very good criteria. Validation from IT experts on the design aspect obtained a percentage of validity of $92.18 \%$ with very good criteria. The results of the validation of field practitioners using the " $r$ product moment" technique (ie the significance of $r$ arithmetic to $r$ table) obtained a significance of $r$ count 0.468 ( $\mathrm{r}$ table) so that it was declared valid.
\end{abstract}

Kata kunci: Pengembangan; Bahan Ajar; Bahasa Arab; Mobile Learning 


\section{PENDAHULUAN}

Munculnya teknologi difusi digital skala besar mengakibatkan pembelajaran berevolusi dari metode tradisional dan telah memasukkan alat-alat baru yang dirancang untuk paling sesuai dengan kebutuhan pembelajar. ${ }^{1}$ Karena penggunaan internet telah meningkat selama beberapa tahun terakhir, komputer menjadi semakin penting dalam sistem pendidikan modern. Pesatnya pengembangan teknologi dan penggunaan internet akan menjadi potensi dalam meningkatkan mutu pendidikan.

Pembelajaran yang meluas saat ini adalah pembelajaran berbasis mobile (mobile learning) yang memanfaatkan perangkat mobile dan berfokus pada mobilitas pembelajar. Dengan adanya teknologi seluler, pola dan gaya hidup peserta didik saat ini berubah. Kecenderungan peserta didik saat ini terhadap penggunaan teknologi seluler telah mengakibatkan kebutuhan akan aplikasi pendidikan untuk dikembangkan menggunakan teknologi. ${ }^{2}$ Guru harus memiliki pemahaman bahwa pelajaran di sekolah harus disampaikan semenarik mungkin, untuk itu kehadiran mobile learning menjadi suatu keniscayaan. Keberadaan perangkat teknologi ini berfungsi sebagai media dalam menyampaikan isi pesan pembelajaran.

Mobile learning adalah teknik hemat biaya yang mendorong peserta didik untuk belajar dan mendapatkan pengetahuan tanpa batasan sistem pendidikan tradisional.3 Dimana dengan pengaplikasian mobile learning dalam pembelajaran akan memungkinkan peserta didik memperoleh materi pembelajaran yang tidak akan terbatas pada ruang dan waktu. Materi yang banyak ataupun sedikit akan bisa disampaikan tanpa harus terbatas oleh waktu pembelajaran dan menjadikan peserta didik belajar secara mandiri sesuai dengan tuntutan kurikulum. Dengan demikian pengaplikasian mobile learning dalam proses pembelajaran dapat dilakukan dalam semua mata pelajaran di sekolah termasuk bahasa Arab.

Materi bahasa Arab disediakan dan disampaikan secara interaktif dan menyenangkan yang merupakan kebutuhan dalam wujud percakapan sehari-hari di sekolah. Pembelajaran bahasa Arab dengan tema الحياة اليومية menuntun siswa agar mudah melafalkan beberapa mufradāt dan penggunaanya dalam konteks kalimat hingga membuatnya menjadi terbiasa dan akrab dengan ungkapan-ungkapan bahasa Arab tersebut. Tentunya materi terintegrasi dalam media yang interaktif.

Berbagai macam penelitian yang terkait dengan pengembangan suatu bahan ajar bahasa Arab berbasis media digital sudah banyak dilakukan oleh para langue developer (pengembang bahasa). Selain itu pula terdapat banyak literatur yang membahas secara fokus mengenai pengembangan suatu bahan ajar melalui program media digital seperti pengembangan bahan ajar bahasa Arab dan bahasa Inggris pada smartphone Android.

Salah satunya penelitian yang dilakukan oleh Juharita (2017) dengan judul "Pengembangan Bahan Ajar Bahasa Arab Berbasis Multimedia untuk Perolehan Belajar AtTa'aruf Siswa Kelas X MAS Al-Qamar Mempwah". Dalam penelitian ini memfokuskan pada pengembangan bahan ajar bahasa Arab berbasis multimedia dengan tujuan agar siswa

\footnotetext{
${ }^{1}$ A. Teodorescu, "Mobile Learning and its Impact on Business English Learning", Procedia - Social and Behavioral Sciences:180. https://doi.org/10.1016/ j.sbspro.2015.02.303 (09 Januari 2019)

${ }^{2}$ Ismail, N. S., Harun, J., Zakaria, M. A. Z. M., \& Salleh, S. M, "The Effect of Mobile Problem-Based Learning Application DicScience PBL on Students' Critical Thinking. Thinking Skills and Creativity 28. https://doi.org/10.1016/j.tsc.2018.04. 002 (7 Januari 2019)

${ }^{3}$ Cohen dalam Sarrab, dkk, An Empirical Study on Cloud Computing Requirements for Better Mobile Learning Services". International Journal of Mobile Learning and Organisation 9, no. 1 ( 2015): h. 1-20
} 
diharapkan mudah dalam memahami materi bahasa Arab At-Ta'aruf dan menjadi bersemangat dalam proses pembelajaran. Selain itu diharapkan agar siswa dapat belajar secara mandiri dalam peningkatan hasil belajar yang ditekankan pada aspek kognitif.

Dalam penelitiannya dijelaskan bahwa problematika pembelajaran bahasa Arab kebanyakan dipengaruhi oleh faktor bahan ajar yang masih bersifat teacher-centered dan sumber belajar yang digunakan kurang menarik. Selain itu, adanya faktor psikis dari dalam diri siswa yang bernaggapan bahwa bahasa arab sangat sulit dan susah yang pada akhirnya kurang menarik untuk dipelajari sehingga mereka tidak semangat dalam pembelajaran dan berdampak pada hasil belajar siswa di bawah nilai standar KKM yang berlaku. Adapun perbedaan dari penelitian ini terhadap permasalahan yang akan diteliti yakni pada aspek media yang berbasis desktop dengan model program yang menunjang peningkatan hasil belajar siswa. $^{4}$

\section{TINJAUAN TEORETIS}

Mobile learning adalah teknik yang menggunakan teknologi seluler dan nirkabel untuk pembelajaran dan pendidikan. ${ }^{5}$ Clark Quinn (Quinn 2000) dalam Majid (2012) mendefenisikan mobile learning sebagai :

"The intersection of mobile computing and e-learning : accesible resources wherever you are, strong search capabilities, rich interaction, powerful support for effective learning, and performance-based assesment. E-learning independent of location in time or space."6

O’Malley et. Al. (2003) dalam Majid (2012) mengatakan bahwa "Mobile learning is ... any sort of learning that happens when the learner is not at a fixed, predetermined location, or learning that happens when the learner takes adventage of learning opportunities offered by mobile technologies." This is similar to john Traxler's (2005) defenition that mobile learning is "... any educational provision where the sole or dominant technologies are handled or palmtop devices." Geddes defined mobile learning as "the acquisition of any knowledge and skill through using mobile technology, anywhere, anytime, that results in an alteration in behaviour."

Berdasarkan defenisi tersebut bahwa mobile learning dapat diartikan sebagai model pembelajaran yang memanfaatkan teknologi dan komunikasi. Pada konsep pembelajaran berbasis mobile learning membawa manfaat ketersediaan materi ajar yang dapat diakses setiap saat dengan visualisasi materi yang menarik.

Tujuan dari pengembangan mobile learning sendiri adalah proses belajar sepanjang waktu (long life learning), peserta didik dapat lebih aktif dalam proses pembelajaran, menghemat waktu karena jika diterapkan dalam proses pembelajaran peserta didik tidak perlu hadir di kelas secara konvesional hanya untuk mengumpulkan tugas melainkan tugas tersebut cukup dikirim melalui aplikasi pada teknologi mobile phone yang secara tidak langsung akan meningkatkan kualitas proses belajar peserta didik.

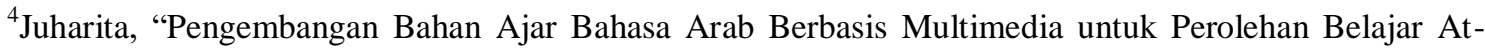
Ta'aruf Siswa Kelas X MAS Al-Qomar Mempwah”, jurnal.untan.ac.id, 2017, h.1-5, https://jurnal.untan.ac.id/ index.php/jpdpb/article/view/23647/0

${ }^{5}$ M. Sarrab, "Mobile Learning (M-Learning) and Educational Environments", International Journal of Distributed and Parallel System, vol 3 no. 4 (July 2012), h. 31-38, https://doi.org/10.5121/ ijdps.2012.3404 (diakses 1 april 2019)

${ }^{6}$ Abdul Majid, "Mobile Learning", jurnal.epi.edu, 2012, h. 4, http://jurnal.upi.edu/file/ Mobile_Learning_ok.pdf
} 
Mobile learning memungkinkan siswa untuk menggabungkan pengalaman belajar mereka dalam lingkungan kolaboratif bersama, saling memberi feedback sehingga memunculkan sesuatu yang sempurna.

\section{METODE PENELITIAN}

Penelitian dan Pengembangan (research and development) digunakan untuk menghasilkan produk, model atau prototipe. ${ }^{7}$ Penelitian ini biasanya menggunakan langkah dan tahapan mulai dari analisa kebutuhan, mencari formula hingga menghasilkan produk, model atau prototipe.

Jenis penelitian ini adalah penelitian dan pengembangan atau disebut dengan istilah research and development dalam Pendidikan, karena penelitian ini berorientasi kepada produk berupa aplikasi bahan ajar bahasa Arab berbasis mobile android. Penelitian ini dilakukan di SMP Muhammadiyah 1 Makassar pada kelas VIII. Penelitian dan pengembangan atau research and development adalah metode penelitian yang digunakan untuk menghasilkan produk tertentu dan menguji keefektifan produk tersebut. ${ }^{8}$ Berdasarkan metode ini, untuk dapat menghasilkan produk tertentu, penelitian ini membutuhkan analisis kebutuhan dan untuk menguji keefektifan produk tersebut supaya dapat berfungsi dalam pendidikan maka dilakukan penelitian uji coba dan validasi produk.

Penelitian ini menggunakan pendekatan penelitian dan pengembangan (research and development), dimana pendekatan penelitian $\mathrm{R} \& \mathrm{D}$ merupakan suatu proses yang digunakan untuk mengembangkan dan menvalidasi produk-produk pendidikan. Berdasarkan hal tersebut, maka penelitian ini menggunakan model prosedural, yaitu menunjukkan langkahlangkah yang harus diikuti untuk menghasilkan produk pembelajaran. Model ini akan menggariskan langkah-langkah umum dalam pengembangan produk yang bisa terdiri dari bahan material, atau rancangan sebagaimana suatu siklus penelitian dan pengembangan dimana objek penelitian berupa bahan ajar bahasa Arab berbasis mobile.

Model pengembangan berupa teori dasar dalam mengembangkan produk yang akan dihasilkan. Model pengembangan dapat berupa model berorientasi kelas, model berorientasi sistem, model berorientasi produk, model prosedural dan model melingkar. Dalam pengembangan ini akan dikemukakan model pengembangan sebagai dasar pengembangan suatu produk pendidikan. Model yang akan dikembangkan adalah mengacu pada model pengembangan dari Hannafin dan Peck. Model Hanafin dan Peck adalah model desain pembelajaran yang terdiri dari empat fase yaitu fase analisis kebutuhan, fase desain, fase pengembangan, fase implementasi serta revisi jika perlu. ${ }^{9}$ Model ini lebih berorientasi produk.

Teknik pengambilan data dalam penelitian ini disesuaikan dengan jenis dan sumber data yaitu kualitatif dan kuantitatif. Data kuantitatif dikumpulkan melalui kuesioner yang diperoleh langsung dari responden yaitu siswa kelas VIII SMP Muhammadiyah 1 Makassar yang dipilih sebagai sampel secara kriteria oleh penulis. Kuesionernya disusun atas pengelompokan pertanyaan yang akan menjadi alat ukur dalam melakukan penelitian ini. Kuesioner terdiri atas pertanyaan tertutup dan terbuka. Data kualitatif dikumpulkan melalui kuesioner dengan pertanyaan terbuka yang disebarkan kepada validator ahli IT dan ahli materi. Sebagian data kualitatif diperoleh dari wawancara dengan responden ataupun

\footnotetext{
${ }^{7}$ Yusring Sanusi Baso, Model Pembelajaran Bahasa Arab Online Berbasis LMS, (Makassar: Prodi Sastra Arab Unhas, 2016)

${ }^{8}$ Sugiyono, Metode Penelitian Kuantitatif, Kualitatif, dan R\&D, (Bandung: CV. Alfabeta, 2011), h. 297.

${ }^{9}$ Muhammad Yaumi, Media dan Teknologi Pembelajaran, h. 97.
} 
observasi peneliti ke penggunaan bahan ajar di sekolah. Selain itu, peneliti mengumpulkan data kualitatif dengan melakukan studi dokumen yang berkaitan dengan kebijakan pengembangan suatu produk dalam pembelajaran sebagaimana penelitian ini berupa penelitian riset dan pengembangan.

Data yang terkumpul dianalisis secara kualitatif ataupun kuantitatif sederhana sesuai dengan instrumen penelitian yang digunakan dan topik masalah yang ingin diteliti. Analisis data yang digunakan disesuaikan dengan jenis data yang dikumpulkan, yakni analisis data mencakup prosedur pengelolaan data, reduksi dan penyajian data baik dengan bagan, tabel atau grafik. Kemudian data diklasifikasikan berdasarkan jenis dan komponen produk yang dikembangkan. Penyajian hasil analisis dibatasi pada hal-hal yang bersifat faktual, dengan tanpa interpretasi pengembang, sehingga dijadikan sebagai dasar dalam melakukan revisi produk. Dalam penelitian ini penulis menggunakan teknik analisis deskriptif dalam menganalisis data yang terkumpul. Analisis deskriptif kualitatif adalah cara analisis yang cenderung kata-kata untuk menjelaskan (descrable) fenomena ataupun data yang dipaparkan. ${ }^{10}$ Selain itu data kuantitatif yang diperoleh dari kuesioner validasi terhadap produk yang telah diujicobakan dianalisis secara kuantitatif dengan pendekatan model TAM. Model TAM merupakan suatu model yang sangat penting secara teoritis dan aplikatif untuk menjelaskan dan memperkirakan penerimaan suatu teknologi, baik secara individu maupun kelompok. ${ }^{11}$

\section{PROSEDUR PENELITIAN}

\section{Tahap Analisis Kebutuhan}

Tahap analisis terdiri dari dua bagian yaitu analisis fungsional dan non-fungsional. Pada analisis (1) fungsional dilakukan analisis kurikulum, yakni pengkajian dan pembahasan tentang kompetensi yang akan terkandung dalam kurikulum. Selain itu analisis tentang learnercharacteristic (karakteristik siswa) melalui wawancara dan observasi, analisis tentang setting (dimana media tersebut dimanfaatkan), dan pada analisis (2) non-fungsional dilakukan analisis kebutuhan sistem yakni hal-hal yang berkaitan dengan perangkat keras dan perangkat lunak yang dibutuhkan dalam memproduksi teknologi pembelajaran (bahan ajar bahasa Arab berbasis mobile learning).

\section{Tahap Desain (Rancangan)}

Tahap perancangan terdiri dari kegiatan penyusunan kerangka struktur isi program dan penyusunan garis-garis besar isi program media. Pada tahap ini diperlukan sketsa desain tampilan layar dalam model storyboard untuk memudahkan pengembang (developer) dalam menterjemahkan ke dalam bentuk yang lebih nyata. Adapun storyboard sebagai berikut:

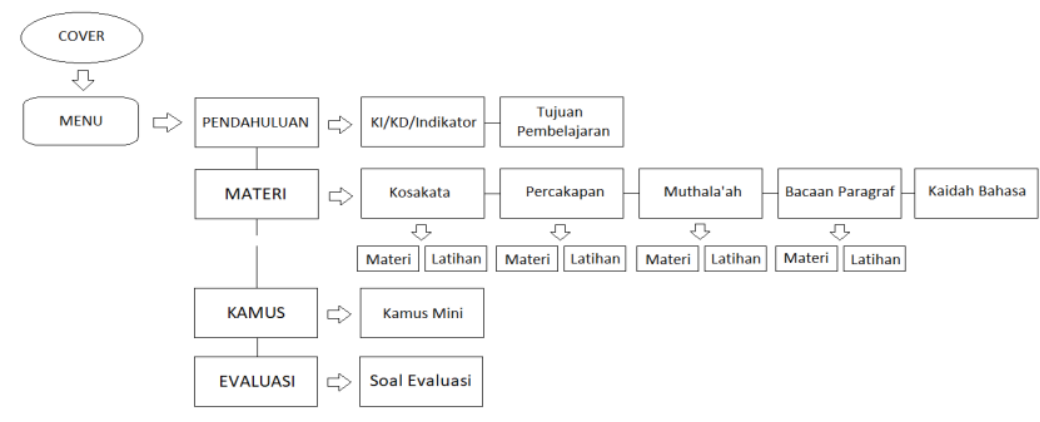

12.

${ }^{10}$ Drajat Suharjo, Metodologi Penelitian dan Penulisan Laporan Ilmiah, (Yogyakarta: UII Press, 2003), h.

${ }^{11}$ Yusring Sanusi B, Model Pembelajaran Bahasa Arab Online Berbasis LMS,. h. 80. 


\section{Tahap Produksi (Development)}

Tahap produksi ini merupakan proses penerjemahan perancangan ke dalam tampilan yang sebenarnya. Tahap produksi terdiri dari kegiatan pembuatan animasi, pengimputan gambar dan audio, pengiputan materi ajar bahasa Arab kedalam program authoring tools, pengemasan (formatting), dan pengkajian proses pengembangan materi ajar bahasa Arab berbasis mobile. Selanjutnya media pembelajaran yang telah melalui proses development ini diperiksa dan diuji terhadap masing-masing skenario yang dirancang sedemikian rupa agar aplikasi ini berjalan dengan baik sesuai tujuannya. Langkah awal pada tahap ini merupakan uji coba produk dalam pemanfaatan dan penyempurnaan. Langkah selanjutnya, program yang dikembangkan diujicobakan kepada beberapa ahli di bidang development terkait program ini dari segi sistem dan materi sebagai validator dari program yang dikembangkan.

\section{Tahap Implementasi dan Evaluasi}

Tahap implementasi yaitu tahap penilaian dan validasi sekaligus proses akhir dari seluruh kegiatan pengembangan. Jika dalam tahap validasi ditemukan beberapa ketidaksesuaian maka akan dilakukan tahap evaluasi yang di dalamnya dilakukan pengubahsuaian untuk memperbaiki kesalahan program.

\section{HASIL PENELITIAN DAN PEMBAHASAN}

Materi yang digunakan dalam pengembangan ini mengenai الحياة اليومية (kehidupan sehari-hari). Bahan ajar bahasa Arab ini dideskripsikan ke dalam 2 bagian yaitu materi ajar berbasis cetak (printed) dan materi ajar berbasis digital (android smartphone). Keduanya ditinjau dari 3 komponen bagian yaitu, bagian pendahuluan, bagian isi, dan bagian penutup (evaluasi).

\section{Desain Bahan Ajar Bahasa Arab}

Bagian pendahuluan mencakup cover tema, kemudian berisi tombol "mulai" untuk menuju ke halaman utama yang terdiri dari menu kompetensi indikator dan tujuan pembelajaran. Bagian cover dalam buku ajar bahasa Arab terdapat tema pembahasan yakni dengan pendekatan saintifik kurikulum 2013. Kemudian bagian menu utama mencakup materi terkait tema dan kompetensi dasar dari tema الحياة اليومية yang menjadi patokan dan acuan dalam pelaksanaan pembelajaran. Dalam bagian ini termasuk indikator pembelajaran.
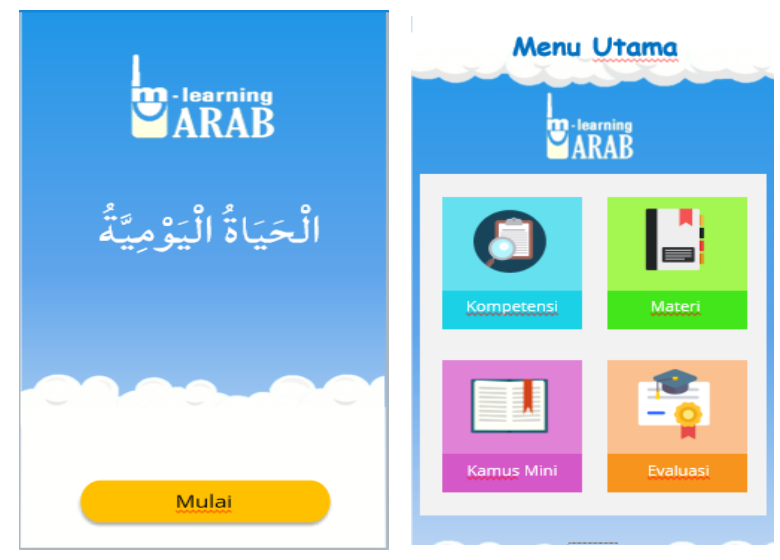

Bagian isi memuat materi pembelajaran yang akan dipelajari. Termasuk di dalamnya latihan soal dari setiap informasi yang bersifat pengetahuan tentang materi dan latihanlatihan yang melatih keterampilan siswa yang berkaitan tema. Pada bahan ajar berbasis 
mobile disajikan dalam bentuk sub-materi yang terdiri dari kosakata, muthala'ah, hiwar, bacaan dan kaidah bahasa
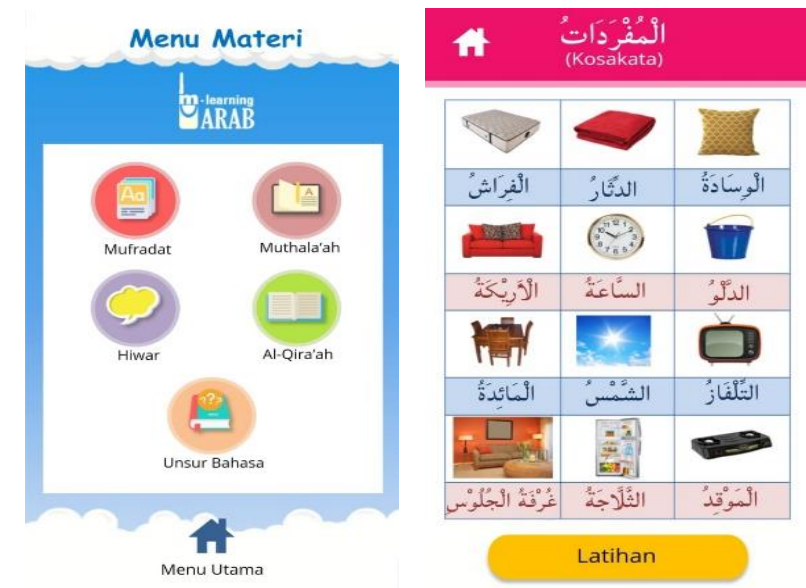

Pada laman kosakata disajikan beberapa kosakata yang berkaitan dengan materi الحياة disertakan gambar dan suara serta lafaz arabnya yang akan memudahkan siswa untuk mengingatnya.

Pada laman muthala'ah berisikan bacaan yang memuat mufradāt (kosakata) baru dengan materi dan unsur kebahasaan yang sama. Hal ini bertujuan agar siswa dapat menyusun dan menerapkan kalimatnya sendiri menggunakan kosakata tertentu yang diberikan.

Pada halaman hiwar terdapat teks percakapan tentang الحياة اليومية yang mesti dipahami oleh siswa dan mesti dipraktekkan agar siswa akrab dengan ungkapan-ungkapan dalam percakapan yang diberikan.
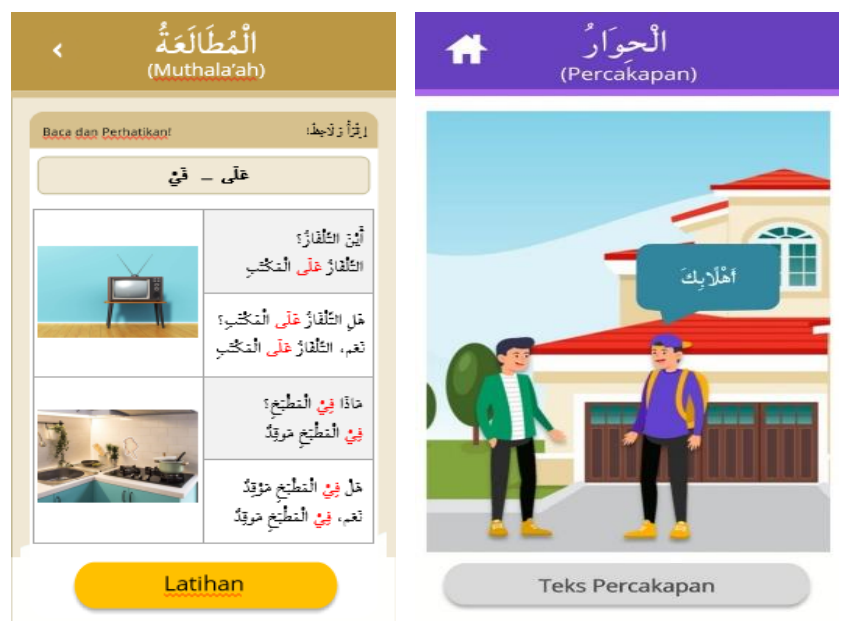

Pada halaman al-Qira'ah terdapat teks bacaan tentang الحياة اليومية yang mesti dipahami oleh siswa agar dapat menjawab soal yang diberikan yang berkaitan dengan wacana.

Pada laman unsur tata bahasa Arab menjelaskan tentang kaidah tata bahasa atau yang berkaitan dengan unsur kebahasaan misalnya pengertian suatu istilah dalam ilmu tata bahasa Arab yakni harf jar serta fungsi dan penggunaanya dalam suatu kalimat. Selain itu, terdapat latihan untuk menguji pemahaman siswa setelah belajar tentang harfjar. 

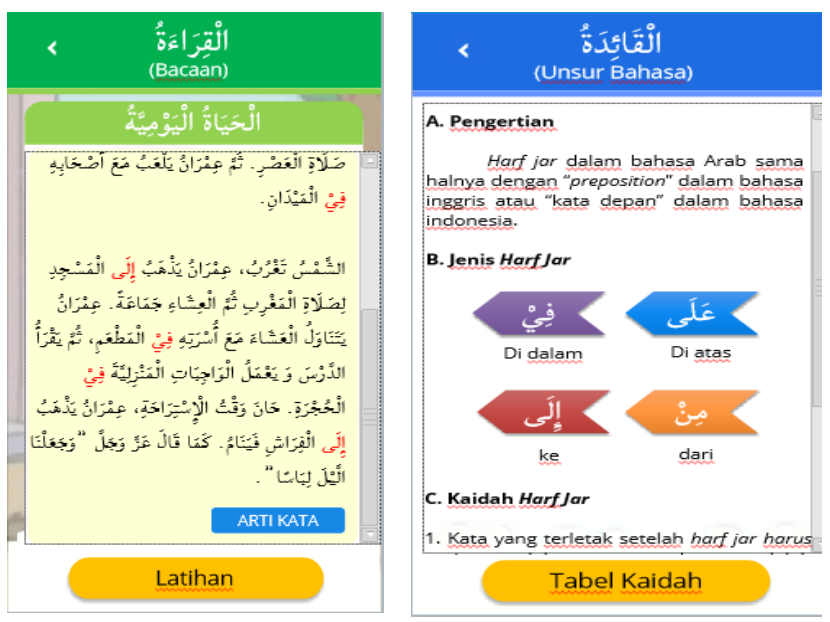

Pada setiap sub-materi berisi latihan-latihan soal yang berdasarkan pengetahuan tentang materi untuk menguji pengetahuan siswa setelah melalui bagian materi.
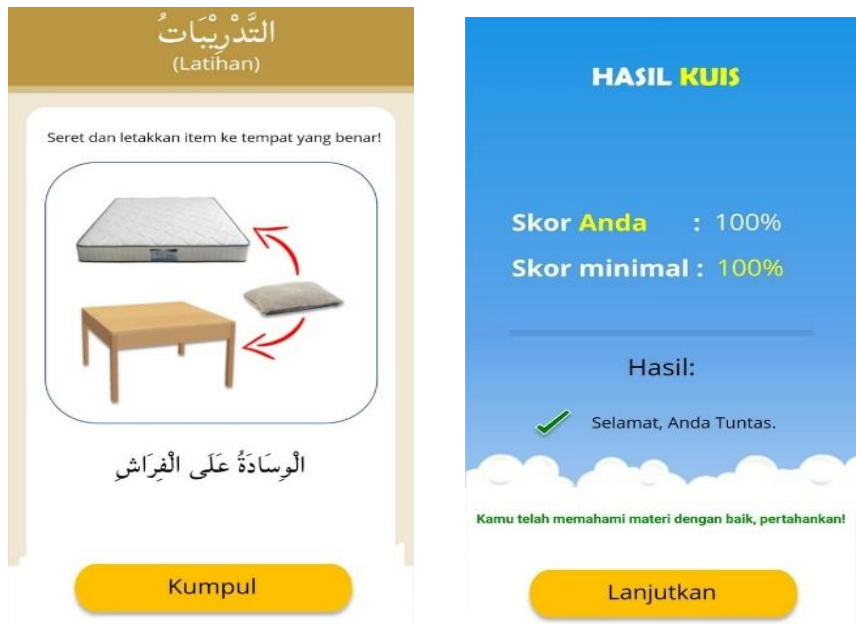

Pada bagian penutup terdapat komponen evaluasi, refleksi, kamus mini dan biografi penulis. Evaluasi berguna untuk menguji secara keseluruhan seluruh isi materi الحياة اليومية baik kosakata, ungkapan, maupun yang berkaitan dengan unsur kebahasaan bahasa Arab.

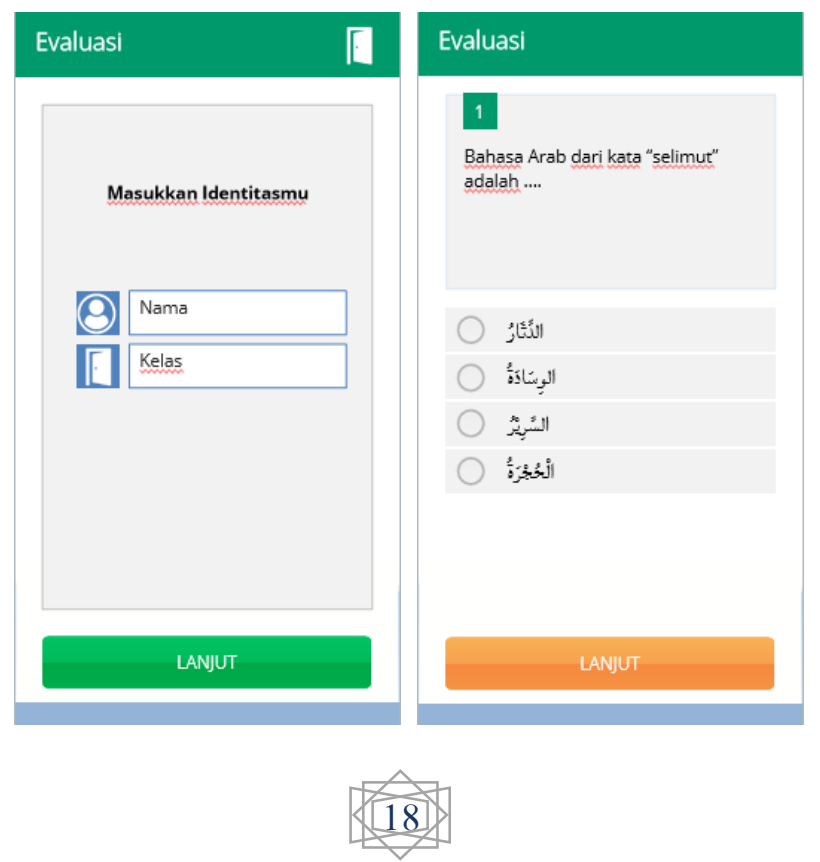


Pada laman evaluasi disajikan model pertanyaan berupa pilihan ganda. Pada laman hasil diberikan feedback dari setiap jumlah jawaban yang benar yang diberikan sehingga pengguna dapat mengetahui ketercapaian belajarnya.

Pada laman kamus mini menyediakan beberapa kosakata-kosakata penting tentang tema الحياة اليومية yang mesti dikuasai oleh siswa.

\section{Hasil Validasi Dan Revisi Produk}

Pengujian dilakukan untuk menilai apakah fungsi-fungsi dalam aplikasi dapat berjalan dengan benar dan untuk mengetahui kekurangan ataupun kesalahan yang harus diperbaiki. Data yang diperoleh dalam penelitian ini berupa data kualitatif dan kuantitatif. Data tersebut diperoleh melalui dua tahap pengujian, yakni validasi ahli dan uji lapangan.

Data validasi terhadap bahan ajar berbasis mobile learning diperoleh dari evaluasi yang dilakukan oleh 2 validator yang terdiri dari validator ahli materi dan validator ahli multimedia pembelajaran. Data kualitatif berupa penilaian tambahan atau saran dari validator, sedangkan data kuantitatif berasal dari skala likert dan keduanya dimuat dalam satu instrumen penilaian atau angket penilaian. Adapun hasil uji validitas terhadap bahan ajar bahasa Arab berbasis mobile learning sebagai berikut.

Validasi ahli materi dilakukan oleh ibu Dr. Dra. Nurtaqwa Amin, M.Hum. Presentase hasil uji validitas setelah dikonversikan dengan tabel konversi skala likert adalah 96\%. Tingkat pencapaian berada pada kualifikasi sangat valid sehingga bahan ajar bahasa Arab berbasis mobile learning tidak perlu direvisi.

Validasi ahli desain media pembelajaran adalah Dr. Andi Agussalim, M.Hum. Presentase hasil uji validitas setelah dikonversikan dengan tabel konversi skala likert adalah $92.18 \%$. Berdasarkan data kualitatif berupa kritik dan saran dari ahli teknologi pembelajaran, telah dituliskan bahwasanya ada aspek yang perlu dikembangkan sebagai bahan penyempurnaan produk sehingga dapat menjadi lebih berkualitas. Segi konten sebagian perlu direvisi dalam perbaikan bahan ajar bahasa Arab berbasis mobile learning ini, yakni agar feedback dalam hasil refleksi agar lebih divariasikan sesuai capaian kinerja pengguna aplikasi bahan ajar berbasis mobile learning.

Setelah diujicobakan kepada ahli pada bidang masing-masing, ditemukan beberapa kekurangan dan kelemahan dari produk yang dihasilkan. Oleh karena itu langkah selanjutnya adalah melakukan revisi kelemahan produk yang telah ditemukan. Adapun bagian kekurangan yang dikritik oleh ahli IT, yakni materi yang disajikan masih kurang jelas. Maka diperlukan materi tambahan untuk penjelasan lebih lengkap. Kemudian bagian dari produk yang perlu direvisi yakni feedback pada setiap hasil kinerja siswa dalam menyelesaikan materi dan latihan. Adapun feedback divariasikan dalam bentuk suara sesuai dengan capaian kinerja setiap siswa selesai mengerjakan latihan dari bab-bab materi yang dipelajari. Peneliti telah meninjau ulang bagian dari produk yang perlu direvisi. Adapun penampilan hasil revisi sebagai berikut:

Pada revisi materi muthala'ah, hal baru yang ditambahkan berupa materi dalam bentuk penjelasan berupa penggunaan "Kata Tanya" pada bab halaman pertama materi muthala'ah. Dalam penjelasan ini dijelaskan mengenai penggunaan kata tanya dalam jumlah mufidah (kalimat sempurna). Penjelasan yang diberikan dalam bentuk sound (suara).

Pada revisi feedback, bagian atau hal baru yang ditambahkan berupa feedback khusus tergantung dari capaian kinerja siswa dalam menyelesaikan latihan setiap bab materi. Di 
setiap latihan terdiri dari feedback yang berbeda-beda dan akan merespon sesuai dengan peningkatan hasil dan proses belajar peserta didik.
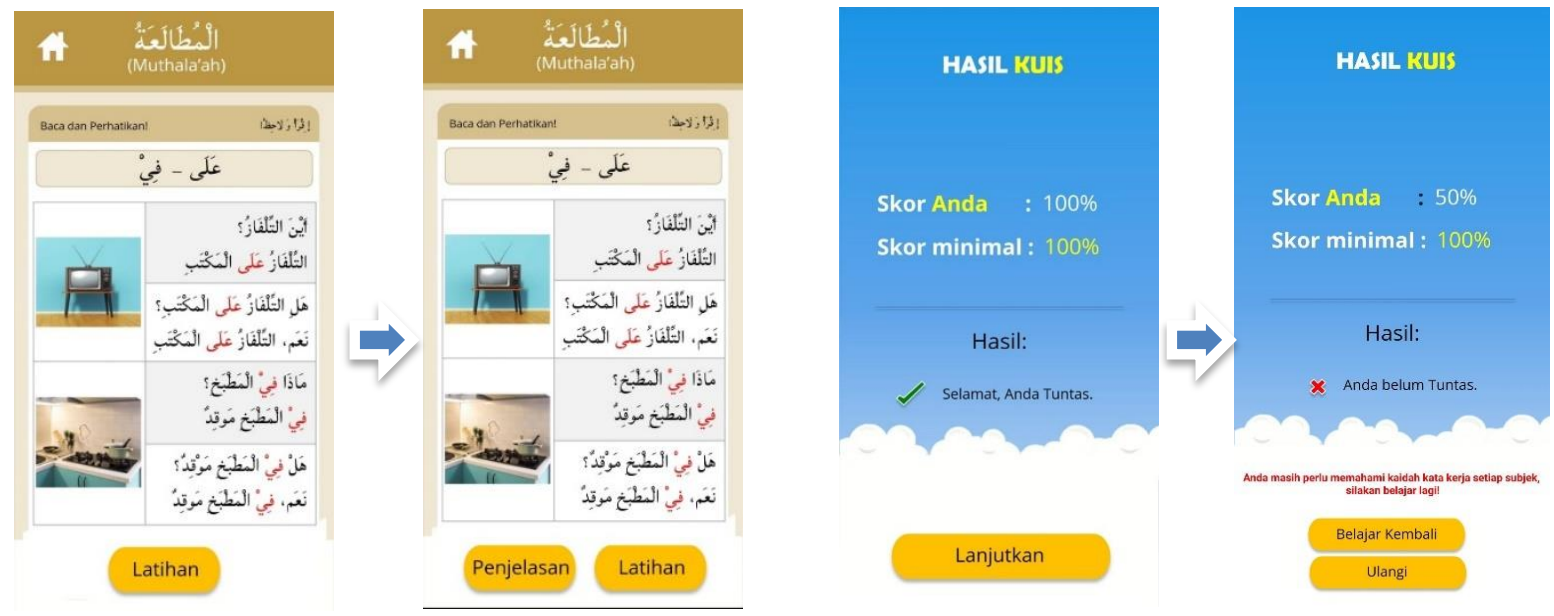

Setelah tahap revisi dilakukan maka produk ujicobakan kembali dalam kondisi nyata. lapangan pada setiap komponen. Kegiatan ini dilakukan pada sasaran siswa kelas VIII di SMP Muhammadiyah 1 Makassar sebanyak 20 siswa yang memiliki tingkat kemampuan yang berbeda. Pertanyaan dalam angket terdiri dari indikator yang diambil dari model Technologi Acceptance Model (TAM).

Uji validitas kuesioner ini dilakukan dengan menghitung nilai korelasi ( $\mathrm{r}$ hitung) dan $\mathrm{r}$ tabel df. Item kuesioner dianggap valid jika nilai $r$ hitung $r$ tabel. Adapun df tabel diperoleh dengan rumus N-2 dimana $\mathrm{N}$ adalah jumlah responden. Dengan demikian, pada uji ini $\mathrm{df}=$ $20-2=18$. Berdasarkan tingkat signifikansi $5 \%$ terhadap df $=18$, diperoleh $\mathrm{r}$ tabel signifikansi 0,468 dan $r$ hitung dari setiap item lebih besar dari $r$ tabel. Sehingga dengan rumus ini diperoleh kesimpulan bahwa semua item kuesioner yang digunakan pada penelitian ini adalah valid.

1) Variabel Perceived Ease of Use

Hasil uji validitas pada variabel Perceived Ease of Use adalah sebagai berikut:

Hasil Uji Validitas Variabel Perceived Ease of Use

\begin{tabular}{cccc}
\hline Indikator & $\mathrm{r}_{\text {hitung }}$ & $\mathrm{r}_{\text {tabel }}(5 \% ; \mathrm{N}=18)$ & Keterangan \\
\hline PEOU1 & 0,599 & 0,468 & Valid \\
\hline PEOU2 & 0,591 & 0,468 & Valid \\
\hline PEOU3 & 0,790 & 0,468 & Valid \\
\hline PEOU4 & 0,741 & 0,468 & Valid \\
\hline
\end{tabular}

Dari tabel di atas dapat diketahui bahwa item pernyataan variabel Perceived Ease of Use dinyatakan valid. Hal ini dapat diketahui $r$ hitung ${ }^{-}$0,468. Sebagaimana telah disebutkan bahwa angka 0,468 merupakan $\mathrm{r}$ tabel yang diperoleh dari $\mathrm{r}$ product moment pada taraf signifikan $(\alpha)=5 \%$ dan $\mathrm{N}(\mathrm{df})=20-2$. 
2) Variabel Perceived Usefulness

Hasil Uji Validitas Variabel Perceived Usefulness

\begin{tabular}{cccc}
\hline Indikator & r hitung & r tabel $(5 \% ; \mathrm{N}=18)$ & Keterangan \\
\hline PU1 & 0,767 & 0,468 & Valid \\
\hline PU2 & 0,630 & 0,468 & Valid \\
\hline PU3 & 0,863 & 0,468 & Valid \\
\hline PU4 & 0,588 & 0,468 & Valid \\
\hline
\end{tabular}

Dari tabel di atas dapat diketahui bahwa item pernyataan variabel Perceived Usefulness dinyatakan valid. Hal ini dapat diketahui $r$ hitung ${ }^{-} 0,468$. Sebagaimana telah disebutkan bahwa angka 0,468 merupakan $\mathrm{r}$ tabel yang diperoleh dari $\mathrm{r}$ product moment pada taraf signifikan $(\alpha)=5 \%$ dan $\mathrm{N}(\mathrm{df})=20-2$.

3) Variabel Attitude Toward Using

Hasil Uji Validitas Variabel Attitude Toward Using

\begin{tabular}{cccc}
\hline Indikator & $\mathrm{r}_{\text {hitung }}$ & $\mathrm{r}_{\text {tabel }}(5 \% ; \mathrm{N}=18)$ & Keterangan \\
\hline ATU1 & 0,761 & 0,468 & Valid \\
\hline ATU2 & 0,700 & 0,468 & Valid \\
\hline ATU3 & 0,897 & 0,468 & Valid \\
\hline ATU4 & 0,824 & 0,468 & Valid \\
\hline
\end{tabular}

Dari tabel di atas dapat diketahui bahwa item pernyataan variabel Attitude Toward Using dinyatakan valid. Hal ini dapat diketahui $\mathrm{r}$ hitung ${ }^{-}$0,468. Sebagaimana telah disebutkan bahwa angka 0,468 merupakan $\mathrm{r}$ tabel yang diperoleh dari $\mathrm{r}$ product moment pada taraf signifikan $(\alpha)=5 \%$ dan $\mathrm{N}(\mathrm{df})=20-2$.

4) Variabel Behavioral Intention to Use

Hasil Uji Validitas Variabel Behavioral Intention to Use

\begin{tabular}{cccc}
\hline Indikator & $\mathrm{r}_{\text {hitung }}$ & $\mathrm{r}_{\text {tabel }}(5 \% ; \mathrm{N}=18)$ & Keterangan \\
\hline BITU1 & 0,699 & 0,468 & Valid \\
\hline BITU2 & 0,778 & 0,468 & Valid \\
\hline BITU3 & 0,814 & 0,468 & Valid \\
\hline BITU4 & 0,757 & 0,468 & Valid \\
\hline
\end{tabular}

Dari tabel di atas dapat diketahui bahwa item pernyataan variabel Behavioral Intention to Use dinyatakan valid. Hal ini dapat diketahui $\mathrm{r}$ hitung ${ }^{-} 0,468$. Sebagaimana telah disebutkan bahwa angka 0,468 merupakan $\mathrm{r}$ tabel yang diperoleh dari $\mathrm{r}$ product moment pada taraf signifikan $(\alpha)=5 \%$ dan $\mathrm{N}(\mathrm{df})=20-2$.

\section{KESIMPULAN}

Produk bahan ajar bahasa Arab berbasis mobile learning telah diuji dan memperoleh validasi dari ahli terhadap produk yang dihasilkan. Hasil menunjukkan bahwa tingkat efektifitas produk bahan ajar bahasa Arab berbasis mobile learning termasuk dalam kriteria penilaian sangat baik dan efektif dari segi penerimaan dan penggunaannya sebagai media dalam pembelajaran bahasa Arab di SMP Muhammadiyah 1 Makassar. Dengan demikian secara umum bahwa bahan ajar bahasa Arab berbasis mobile learning yang telah dikembangkan ada pada kualifikasi sangat baik sehingga layak untuk digunakan sebagai salah satu media alternatif dalam membelajarkan bahasa Arab khususnya kepada siswa SMP Muhammadiyah 1 Makassar. 
Berikut ini merupakan saran-saran untuk pengembangan lebih lanjut terhadap bahan ajar bahasa Arab berbasis mobile learning agar dapat lebih memberikan manfaat terhadap kepentingan akademik. Guru bisa memanfaatkan produk sebagai media alternatif dalam pembelajaran bahasa Arab. Siswa memiliki produk pembelajaran ini dapat dijadikan sebagai salah satu sumber belajar mandiri. Sekolah dapat mempertimbangkan sebagai salah satu bahan ajar bahasa Arab di kelas. Aplikasi ini ditujukan secara meluas bagi siapa saja yang mempelajari dan ingin mempelajari bahasa Arab berbasis mobile learning. Berdasarkan masukan dari ahli bahwa produk ini tidak terlepas dari ketidaksempurnaan, maka dari itu pada sistem yang selanjutnya dapat dikembangkan hingga menjadi produk yang lebih baik dan lebih efektif lagi.

\section{DAFTAR REFERENSI}

Baso, Yusring Sanusi. 2016. "Model Pembelajaran Bahasa Arab Online Berbasis LMS". Makassar: Prodi Sastra Arab Unhas. h. 80.

Ismail, N. S., Harun, J., Zakaria, M. A. Z. M., \& Salleh, S. M. 2018. The effect of Mobile problem-based learning application DicScience PBL on students' critical thinking. Thinking Skills and Creativity 28.

Juharita. 2017. "Pengembangan Bahan Ajar Bahasa Arab Berbasis Multimedia untuk Perolehan Belajar At-Ta'aruf Siswa Kelas X MAS Al-Qomar Mempwah". jurnal.untan.ac.id. h.1-5.

Majid, Abdul. Perencanaan Pembelajaran. Bandung: PT. Remaja Rosdakarya. 2007.

Sarrab, M. \& M. Elbasir. 2016. Mobile learning: a state-of-the-art review survey and analysis. International Journal of Innovation and Learning.

Sarrab, M, Alalwan, N., Alfarraj, O., \& Alzahrani, A. 2015. An empirical study on cloud computing requirements for better mobile learning services. International Journal of Mobile Learning and Organisation. 9(1).

Sarrab, M. 2012. Mobile Learning (Mobile learning) and Educational Environments. International Journal of Distributed and Parallel System.

Sugiyono. 2011. Metode Penelitian Kuantitatif, Kualitatif, dan R\&D. Bandung: CV. Alfabeta.

Suharjo, Drajat. 2003. Metodologi Penelitian dan Penulisan Laporan Ilmiah. Yogyakarta: UII Press.

Teodorescu, A. 2015. Mobile Learning and its Impact on Business English Learning. Procedia - Social and Behavioral Sciences: 180 .

Yaumi, Muhammad. 2018. Media dan Teknologi Pembelajaran. Jakarta: PrenadaMedia Group 